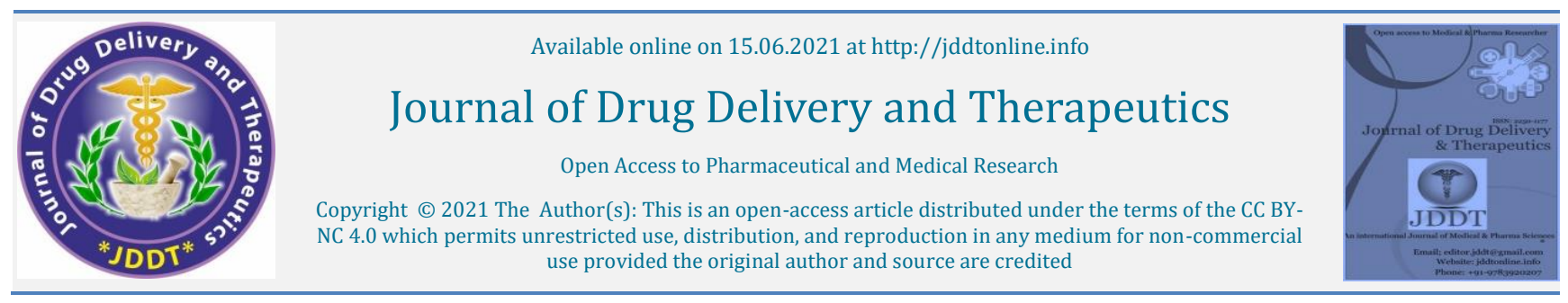

Open Access Full Text Article

\title{
Formulation and Evaluation of Immediate Release Tablet Dosage Form of Linagliptin and Metformin Hydrochloride
}

\author{
Sukanta Chatterjee*, Rakesh Kumar Jat \\ Institute of Pharmacy, Shri Jagdishprasad Jhabarmal Tibrewala University, Jhunjhunu, Rajasthan - 333001, India
}

\begin{tabular}{ll}
\hline Article Info: & \\
\hline$\square$ & Article History: \\
& $\begin{array}{l}\text { Received 08 April 2021 } \\
\text { Review Completed 25 May } 2021\end{array}$ \\
\hline
\end{tabular}

Cite this article as:

Chatterjee S, Jat RK, Formulation and Evaluation of Immediate Release Tablet Dosage Form of Linagliptin and Metformin Hydrochloride, Journal of Drug Delivery and Therapeutics. 2021; 11(3-S):61-64 DOI: http://dx.doi.org/10.22270/jddt.v11i3-S.4831

\section{*Address for Correspondence:}

Sukanta Chatterjee, Institute of Pharmacy, Shri Jagdishprasad Jhabarmal Tibrewala University, Jhunjhunu, Rajasthan - 333001, India

\author{
Abstract
}

The aim of the current study work was to formulate and assess a fixed dose mixture tablet of instant release oral solid dosage form comprising two anti-diabetic drugs (linagliptin and metformin hydrochloride) for managing of diabetes mellitus type 2.The innovator drug product (Jentadueto Tablet) was evaluated for the various evaluation parameters, which have been taken into consideration during the drug product development. Pre-formulation evaluation was accomplished to safeguard better parameters of formulated drug product. On the result of pre-formulation evaluation and innovator drug product characterization, the model drug product was recognized in various steps. The established formulation was augmented for different excipients. The instant release film covered tablet of linagliptin and metformin $\mathrm{HCl}$ was expressed and augmented at laboratory scale. The individual steps (procedures) were improved for the same and the scale-up contemplation have been engaged into account certify the product performance at pilot plant-up to commercial scale-up.

Keywords: anti-diabetic, linagliptin, metformin

\section{INTRODUCTION}

Major causes of death during last decade are coronary heart disease (cardiac problem), stroke, chronic pulmonary obstructive disease (COPD), diabetes mellitus and lower respirational infections. The diabetes instigated 1600000 (2.8\%) deaths in 2015, up from 1000000 (1.8\%) demises in 2000 1,2. As per report of International Diabetes Federation, the projected number of diabetic patients (age group 20-79 years) in global prevalence are 463.0 million, 578.4 million and 700.2 million in 2019, 2030 and 2045, respectively. Thus, in global prevalence, the diabetic patients are increase day-by-day; as number of patients are increased yearly in top diabetic countries. From these data, it seems that all countries are playing a game (diabetes disease) and competes to become a winner player (first position in number of diabetic patients). Surprisingly, from the present data analysis, the number of diabetic patients in Pakistan would be higher than USA in 2045.

Diabetes is one of the most common non-communicable disease globally and it is two types: Diabetes mellitus metabolic disorder characterized with elevated level of blood sugar. Diabetes insipidus - metabolic disorder of salt and water metabolism characterized by strong thirst and heavy urination. As per World Health Organization (WHO), "diabetes mellitus is a chronic, metabolic disease characterized by elevated levels of blood glucose (or blood sugar), which leads over time to serious damage to the heart, blood vessels, eyes, kidneys, and nerves".

The FDC has been well advocated by Halimi S. et. al and Gohel N. et.al by effectively described single tablet of vildagliptin and metformin for the management of type II, that has proved better control of glycaemic control and enhanced patient compliance ${ }^{3-4}$. Similarly, Blonde L. et. al has been encouraged for the FDC as therapy for type 2 diabetes mellitus by giving numerous examples of the same 5. In the same way, bilayer tablet of vildagliptin and metformin was articulated in the form of matrix tablet as instant release of vildagliptin and prolonged release of metformin over the 12 hours. The crospovidone (superdisintegrant, 10\%) and gaur gum (controlled release polymers, $30 \%$ ) were used for the immediate release and sustained release layer, respectively ${ }^{6}$. Kupsal $\mathrm{K}$ et. al has been also summarized the dose of metformin with all the antidiabetic classes for the management of glycaemic control in diabetic patients ${ }^{7}$. Fenugreek mucilage was used for bioadhesive agent to prepare sustained release layer of the metformin consisting Carbopol 934P (rheology modifier), sodium alginate (binding agent), both grade of hydroxypropyl methylcellulose (HPMC K4M and HPMC K $100 \mathrm{M})$. As similar with other reports, vildagliptin was also compressed with super-disintegrating agent to prepare 
immediate release layer of bilayer tablet to treat patients with type II diabetes $\mathbf{8}^{\text {. }}$

A combination therapy of metformin hydrochloride (MET) and linagliptin (LINA) achieves a perfect glycemic control in person with diabetes. Present work is focusing towards formulation of immediate release formulations of metformin hydrochloride and immediate release linagliptin in a single layer. Object of the current research work is to formulate and develop a tablet of fixed dose of quick release oral solid dosage form containing anti-diabetic drugs (linagliptin DPP-inhibitor and metformin - biguanide) for management of type-II diabetes. Thus, the aim of current research was to articulate static dose amalgamation of two anti-diabetic medicines (linagliptin and metformin hydrochloride) in which they are envisioned for instantaneous drug action.

\section{EXPERIMENTAL}

\section{Formulation development}

Pre-formulation studies viz. solubility, particle size distribution, compressibility index, drug-drug interaction, drug-alkalizing agent interaction were performed to ensure better parameters of developed product. On the basis of preformulation study and reference product characterization, the prototype formulation was developed in different steps vis. excipient selection, feasibility trial, dissolution test. The developed formula was optimized by dissolution studies.

\section{RESULT AND DISCUSSION}

\section{Pre-formulation study}

The pre-formulation parameters viz. solubility of APIs (linagliptin and metformin $\mathrm{HCl}$ ), particle size distribution, compressibility index of the powder, tapped and bulk density of the powders of the APIs, powder microscopy of APIs and drug-drug interaction study would enlighten the track of the product development of proposed study.

Solubility - Linagliptin was found to exhibit pH-dependent solubility in aqueous media, where solubility was found to be high in acidic media and decreased with an increase in the $\mathrm{pH}$ of the media Thus, it has been concluded that the linagliptin is highly soluble over a $\mathrm{pH}$ range of 1.2-7.4 as per BCS (Biopharmaceutics classification system).In the similar fashion, the solubility of metformin hydrochloride was also performed in different buffers including water. It was observed in between $266.24-324.59 \mathrm{mg} / \mathrm{mL}$, which is indication of the freely soluble drug in water its different buffers.

Compressibility index- For linagliptin, it was found to be $28.54 \%$, which was determined from the tapped density $(0.701 \mathrm{mg} / \mathrm{mL})$ and bulk density $(0.501 \mathrm{mg} / \mathrm{mL})$ of the linagliptin powder. This compressibility index (28.54\%) has poor flow property but the dose of linagliptin $(2.5 \mathrm{mg})$ was very low compare to total weight of the tablet or powder to be tablet. Similarly, the compressibility index of metformin $\mathrm{HCl}$ was found to be $31.22 \%$, which was determined from the tapped density $(0.771 \mathrm{mg} / \mathrm{mL})$ and bulk density $(0.530$ $\mathrm{mg} / \mathrm{mL}$ ) of the metformin $\mathrm{HCl}$ powder. The poor compressibility index (31.22\%) of metformin was observed which leads to capping during tableting (Table 1).

Drug-drug interaction \& stabilizer - Metformin hydrochloride in the presence of water (moisture) is less likely to interact with linagliptin and may results in the formation of $\mathrm{N}$-acetyl derivative. Therefore, due to decreased level of total impurities related to linagliptin with meglumine, meglumine was best stabilizer for the proposed combined fixed dosage form of linagliptin and metformin $\mathrm{HCl}$ and it was selected for the further optimization of other excipients.

Table 1: Results of pre-formulation study of linagliptin and metformin $\mathrm{HCl}$

\begin{tabular}{|l|l|l|}
\hline Parameter & Linagliptin & Metformin HCl \\
\hline Solubility & $\begin{array}{l}\text { Soluble in 0.1N HCl (pH 1.1) \& acetate } \\
\text { buffer (pH 4.5) }\end{array}$ & $\begin{array}{l}\text { Soluble in 0.1N HCl (pH 1.1), acetate buffer (pH 4.5), } \\
\text { phosphate buffer (pH 6.8 \& 7.4) and water }\end{array}$ \\
Coarse grade & $\mathrm{D}(0.9)=498.4 \mu \mathrm{m}$ & $\mathrm{D}(0.9)=8.6 \mu \mathrm{m}$ \\
Fine grade & $\mathrm{D}(0.9)=104.4 \mu \mathrm{m}$ & $\mathrm{D}(0.9)=4.7 \mu \mathrm{m}$ \\
Compressibility index & $28.54 \%$ & $31.22 \%$ \\
Powder microscopy & White to yellow powder & White crystalline powder \\
\hline
\end{tabular}

The pre-formulation study was performed to evaluate powders characteristic parameters (solubility, particle size distribution, compressibility index and powder microscopy) of drugs (linagliptin and metformin $\mathrm{HCl}$ ), drug-drug interaction and drug-alkalizing agent interaction. After selection of excipients of immediate release tablet (i.e. development of formula of tablet), the feasibility trials were performed for method of granulation (fluid bed granulation), friability of core tablets, hardness, assay, impact of particle size of APIs (linagliptin and metformin $\mathrm{HCl}$ ), impact and quantity of meglumine (as alkalizing agent).

\section{Prototype Formulation Development}

The major difference between the innovator product (Jentadueto) and proposed FDC product that the Jentadueto consists of L-arginine as stabilizer in the core tablet, whereas meglumine was included in the proposed product. Both proposed formulation and the RLD comprise standard excipients consistent with the design of immediate release solid oral dosage form. On the basis of pre-formulation studies and innovator product (Jentadueto) characterization, the unit formulas for immediate release tablets of linagliptin and metformin hydrochloride in all the strengths $(2.5$ $\mathrm{mg} / 1000 \mathrm{mg} ; 2.5 \mathrm{mg} / 850 \mathrm{mg} ; 2.5 \mathrm{mg} / 500 \mathrm{mg}$ ) were finalized (Table 2). 
Table 2: Formula of immediate release tablet of linagliptin and metformin $\mathrm{HCl}$

\begin{tabular}{|c|c|c|c|}
\hline Ingredients & $\mathrm{mg} / \mathrm{tab}$ & $\% w / w$ & Remark \\
\hline \multicolumn{4}{|l|}{ Intragranular core part } \\
\hline Metformin $\mathrm{HCl}$ & 1000 & 85.47 & Active ingredient \\
\hline Linagliptin & 2.5 & 0.21 & Active ingredient \\
\hline Co-povidone & 90.00 & 7.69 & Binder \\
\hline Meglumine & 8.00 & 0.68 & Stabilizer \\
\hline Purified water & q.s. & q.s. & Granulating fluid \\
\hline \multicolumn{4}{|l|}{ Extra-granular part } \\
\hline Corn starch & 25.50 & 2.18 & Diluent \\
\hline Colloidal silicon dioxide & 4.00 & 0.34 & Glidant \\
\hline Magnesium stearate & 10.00 & 0.85 & Lubricant \\
\hline Core tablet weight & 1140 & 97.43 & - \\
\hline \multicolumn{4}{|l|}{ Film coating } \\
\hline Opadry pink & 30.00 & 2.56 & Coating material \\
\hline Purified water & q.s. & q.s. & Coating solvent \\
\hline Coated tablet weight & 1170.0 & 100.00 & - \\
\hline
\end{tabular}

The preliminary risk valuation of influence of study variables on product critical quality attributes (CQAs) was analyzed to ensure optimized formulation. The key factor of formulated dosage form was dissolution profile of product, which was governed by medium risk factors (quantity of corn starch and co-povidone). Similarly, quantity of meglumine was evaluated as medium risk for the related substances. In this context, the quantity of corn starch, co-povidone, stabilizer (meglumine), colloidal silicon dioxide and Opadry to ensure the low risk factor.

Uniformity and assay of dosage form - The \% assay of linagliptin and metformin $\mathrm{HCl}$ in both strengths were found within the limit as $101.2 \%$ and $100.4 \%$ (middle strength) and $100.0 \%$ and $100.6 \%$ (lower strength), respectively (Fig. 1). Similarly, the uniformity of dosage form for linagliptin was performed as low dose content (linagliptin) in tablet was very important than higher dose content (metformin $\mathrm{HCl}$ ). It was observed for middle and lower strength tablets in between $100.9-103.3 \%$ and $98.6-99.9 \%$, respectively (Fig. 2).

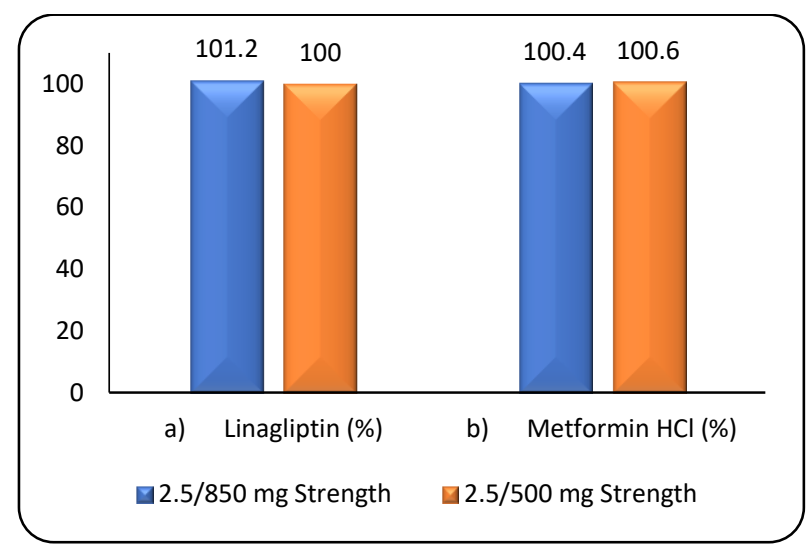

Figure 1: Assay of finished tablets (middle and lower strengths)

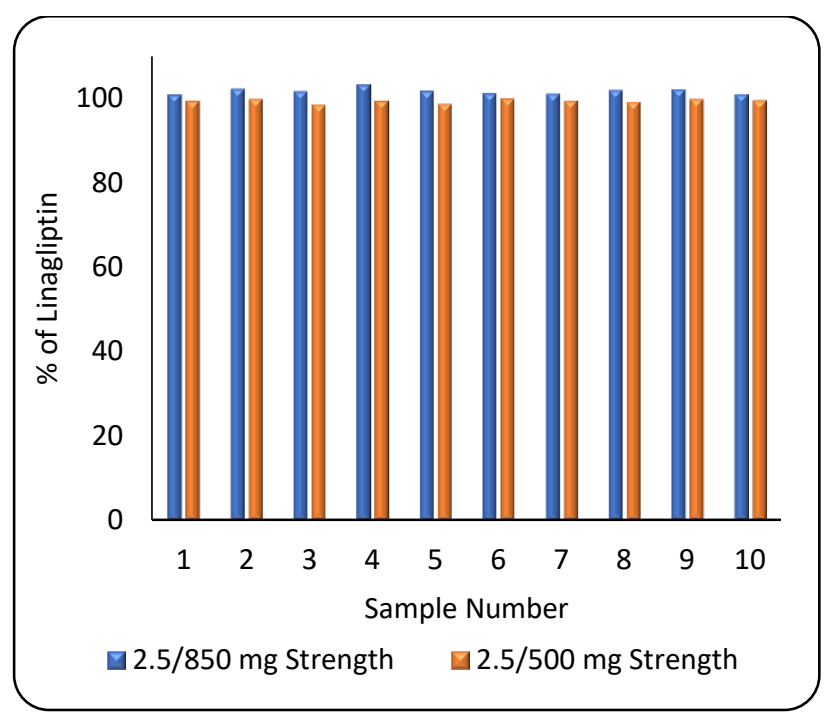

Figure 2: Uniformity of dosage form (Linagliptin)

Dissolution profile - The dissolution profile middle and lower strengths of the test formulations were about 10-25\% faster than the reference product strengths. As per bioequivalence study; it has been observed that difference of $10-15 \%$ in the dissolution no significant impact on the therapeutic effect of the dosage form. It was proposed that the $10-25 \%$ difference observed between the three strengths was unlikely to have an impact on the in-vivo performance of the test product and was therefore considered to be acceptable. More than $90 \%$ drug content (linagliptin and metformin $\mathrm{HCl}$ ) from all the strengths (higher, middle and lower) was released within 15-20 min (Fig. 3). 


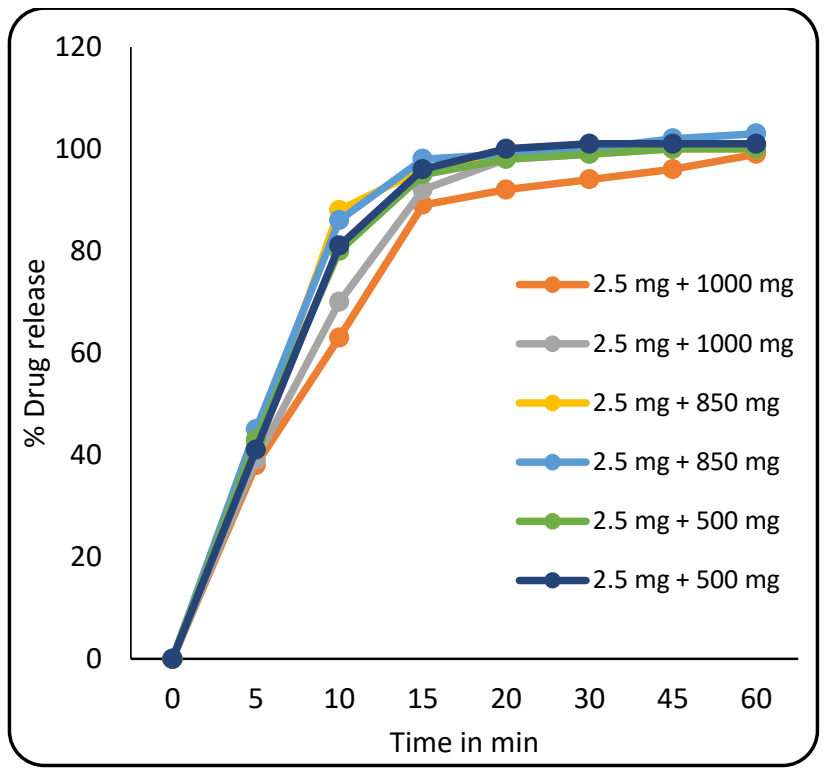

Figure 3: Comparative dissolution profile of three strength tablets

\section{CONCLUSION}

The immediate release layer tablet of linagliptin and metformin $\mathrm{HCl}$ was formulated and characterized at laboratory scale by using meglumine as alkalizing agent (stabilizer). The stabilizer prevents drug-drug interaction between both APIs of the formulated dosage form. It is recommended that in-vitro-in-vivo correlation (IVIVC) of the formulated drug product can be performed to ensure the optimization of the articulated dosage form.

\section{REFERENCES}

1. Sicree R., Shaw J., Zimmet P. Prevalence and projections. In: Gan D (ed.). Diabetes Atlas International Diabetes Federation, $3^{\text {rd }}$ edn. International Diabetes Federation, Brussels, Belgium, 2006; 16104.

2. Clifford J. Bailey., Caroline D. Antidiabetic drugs, The British Journal of Cardiology, 2003; 10:128-36.

3. Halimi S., Schweizer A., Minic B., Foley J., Dejager S. Combination treatment in the management of type 2 diabetes: focus on vildagliptin and metformin as a single tablet, Vascular Health and Risk Management, 2008; 4(3):481-492.

4. Gohel N., Patel D.M., Patel K., Modi J. Formulation Development and Evaluation of Modified Release Tablet using a Fixed Dose Combination of Antidiabetic Agents, International Journal of Pharmaceutical Sciences Review and Research, 2017; 42(2):139145.

5. Blonde L., Juan Z.T.S. Fixed-Dose Combinations for Treatment of Type 2 Diabetes Mellitus, Advances in Therapy, 2012; 29(1):113. DOI 10.1007/s12325-011-0094-1.

6. Khan M.D.P., Basha S.A.A., Mudabbir M.A.H. Formulation and Evaluation of Bilayer Matrix Tablets for Controlled Delivery of Metformin $\mathrm{HCl}$ and Vildagliptin, 2014; 6(2):6739-6756.

7. Kupsal K., Mudigonda S., Nyayapathi V.B.K.S., Neelala K., Hanumanth S.R. Metformin Combinatorial Therapy for Type 2 Diabetes Mellitus, Journal of Metabolic Syndrome, 2016; 5:210. doi: 10.4172 / 2167-0943.1000210.

8. Prajapati T.K. Development and Evaluation of Combination Formulation for the Immediate Delivery of Vildagliptin $\mathrm{HCl}$ and the Sustained Delivery of Metformin, International Journal of Current Advanced Research, 2018; 74:12097-12104. 